\title{
KHAN, Shamus (2012). Privilege. The making of an adolescent elite at St. Paul's School. Princeton and Oxford: Princeton University Press. 232pp. (Collection - Princeton Studies in Cultural Sociology). ${ }^{1}$
}

\author{
Nicolau Dela Bandera Arco Netto * \\ http://dx.doi.org/10.1590/0103-7307201507712
}

\author{
* Universidade de São Paulo, \\ Doutorando do Programa de Pós-Graduação em \\ Antropologia Social, São Paulo, São Paulo, Brasil. \\ nicolaudelabandera@gmail.com
}

S

t. Paul's School tem sido a segunda casa de uma fração significativa da elite nos Estados Unidos. Como um internato em Concord, New Hampshire, essa escola de Ensino Médio caracteriza-se por preparar seus estudantes para o ingresso nas universidades da Ivy League ${ }^{2}$. O premiado livro de Shamus Khan - professor do departamento de sociologia da Columbia University e diretor do grupo de pesquisa sobre a "influência política das elites econômicas", financiado pela Russell Sage Fundation em Nova York - sobre esse internato lança luz para o tema do papel das escolas na (re)produção das desigualdades culturais e econômicas a partir do estudo das elites, questão que tem sido extensamente pesquisada pela sociologia da educação brasileira nas últimas décadas (Almeida, 2009; Canêdo, Almeida, Garcia \& Bittencourt, 2004; Nogueira, 2004).

Khan optou por iniciar seu livro com uma descrição da trajetória de sua própria família, apresentando o que os antropólogos denominam sua "positionality na pesquisa”, ou seja, a experiência social acumulada que o autor carrega

1. Apoio: Fundação de Amparo à Pesquisa do Estado de São Paulo 2. As mensalidades do colégio giravam em torno de 40.000 dólares anuais no começo da década de 2000. 0 termo Ivy League é utilizado para designar um grupo de oito universidades na costa nordeste dos Estados Unidos, reconhecidas internacionalmente por seu prestígio acadêmico e pela alta seletividade de seu público, realizada por processos não muito explícitos de avaliação das qualidades (comportamentais, sociais, esportivas e acadêmicas) dos estudantes. Dentre tais instituições, podemos mencionar Harvard, Yale, Princeton e Columbia. 
consigo para o trabalho de campo e que influenciará sua inserção assim como os resultados da etnografia. Como um ex-estudante não muito convencional de St. Paul - seu pai é oriundo de uma região rural do Paquistão e sua mãe de uma área rural na Irlanda, ambos recém-chegados à elite americana -, o autor lança o desafio de estranhar o familiar, questionando alguns pressupostos tidos como naturais sobre a reprodução da elite nos Estados Unidos e sobre o colégio em particular, tais como a ideia de que o colégio é um reduto fechado e que reproduz as desigualdades no sistema de ensino por meio da transmissão de conhecimentos eruditos inacessíveis aos estudantes provenientes das classes trabalhadoras e médias.

A exclusividade e o fechamento da elite em si mesma, segundo o autor, não são mais as engrenagens centrais do mecanismo de reprodução desses grupos sociais. Resultado, em parte, das mudanças sociais pós-movimentos pelos direitos civis nos Estados Unidos, que desafiaram a exclusão característica das instituições de elite, uma nova elite, segundo o autor, desenvolveu-se no país, reivindicando maior abertura às minorias étnicas. Contudo, essa "sociedade mais aberta" não significou uma redução das hierarquias e das desigualdades econômicas. 0 autor cunhou um oximoro provocador para descrever esse relativo paradoxo: uma "desigualdade democrática”, ou seja, há uma pequena abertura das instituições de elite para novos ricos, alguns provenientes de minorias étnicas, ao mesmo tempo em que a concentração da riqueza tende a ser maior, e a desigualdade entre as classes sociais tende a se exacerbar.

Não surpreende que algumas questões lançadas por Tocqueville ainda ecoem nos debates sobre o sistema de ensino nos Estados Unidos. A desigualdade é mais tolerada, argumenta Khan, quando seu caráter é percebido como justo. Dessa forma, no lugar da prerrogativa adquirida por nascimento (entitlement), os estudantes do colégio incorporam a ideologia do mérito individual e do trabalho árduo para justificar sua posição privilegiada no sistema de ensino. 0 privilégio, como o autor enfatiza ao longo de todo o livro, não será caracterizado pelo acúmulo de conhecimentos eruditos e pela criação de fronteiras e obstáculos para que outros não sejam capazes de se apoderar deles, mas pela disposição de estar e se sentir sempre à vontade nos mais variados ambientes e situações, tais como, por exemplo, em um almoço com os professores em traje de gala, em uma palestra ministrada no colégio por um renomado escritor contemporâneo, assim como em 
uma discussão entre os colegas sobre os grupos de hip hop no dormitório da escola. Ao abraçar o ideal de uma "sociedade aberta”, os estudantes demonstram certo "radicalismo igualitário em seus gostos", um apetite onívoro pela cultura popular e de elite.

Os estudantes que apresentam certo esnobismo, enfatizando sua origem aristocrática, não são aqueles que triunfam academicamente ou se tornam os mais populares no colégio. Ao contrário, eles experimentam certo ostracismo. Esse é o caso do jovem Chase Abbott, estudante que pertence a uma família que há gerações frequenta a instituição. Os demais estudantes o acusam de estar no colégio não por causa de suas qualidades pessoais, mas por causa de sua família, um nepotismo não tolerado por esses jovens que creem que seu sucesso escolar e a presença em St. Paul se devem exclusivamente ao próprio esforço e talento. Essa valorização do mérito é, em parte, explicada pelo autor por uma transformação estrutural na elite americana, que não vê mais sua riqueza ser construída pelo acúmulo e pela herança de um capital industrial tal como na geração dos herdeiros de Rockfeller e Ford. A renda de parte significativa das famílias dos estudantes provém de empregos em multinacionais e/ou no Estado, ainda que a herança de propriedades não tenha desaparecido do horizonte. Os estudantes aprendem a enfatizar, portanto, o trabalho duro e o talento, como explicação para sua boa fortuna. Os estudantes sempre dizem, assim como os professores, que "há muito trabalho para ser feito". Descobrimos pela etnografia do autor que muitos estudantes assistiam à televisão e a filmes em seus computadores pessoais nos dormitórios. Eles tentam evitar serem vistos não trabalhando pelos professores e seus pares.

A etnografia de Khan demonstra, assim, que uma "sociedade aberta” não significa uma sociedade mais igualitária. Uma lição constante do colégio é que a hierarquia sempre se faz presente, como uma presença natural. 0 ritual de abertura do ano letivo, descrito no capítulo "Finding one's place", demonstra o aprendizado corporal da intensidade das relações de hierarquia que são parte das instituições de elite. Tal ritual é realizado no espaço mais coletivo do local, a capela, e é organizado de maneira extremamente hierárquica. Conforme os estudantes avançam nas séries, eles ocupam, na capela, um banco mais próximo dos professores, aproximando-se da vida adulta e distanciando-se dos colegas mais novos.

Outra forma perspicaz, encontrada pelo autor, para descrever o aprendiza- 
do corporal da hierarquia é a observação das interações entre os estudantes e os funcionários que, diferentemente dos professores e dos estudantes, não moram no campus. Ao construir relações de intimidade com os funcionários, os estudantes aprenderam como interagir com quem está abaixo deles na hierarquia social, desenvolvendo uma habilidade para cruzar certas fronteiras entre as classes sociais. Contrariando um pressuposto do autor ao iniciar sua pesquisa, os estudantes bolsistas (por volta de um terço do corpo discente), recrutados nas classes trabalhadoras e médias, demonstraram mais dificuldade para interagir com os funcionários, pois as posturas corporais deles recordavam os bolsistas, constantemente, da hierarquia que os separa dos mais bem afortunados no colégio.

$\mathrm{Na}$ interação com os professores, a relação é mais ambígua. Os estudantes e os professores, que também residem na escola, dispendem a maior parte de seu tempo juntos, nos jantares ritualizados e nas muitas atividades oferecidas pelo colégio. Espera-se dos professores que eles atuem como educadores, conselheiros, técnicos esportivos e disciplinadores dos estudantes. Os alunos desenvolvem, portanto, uma relação de intimidade densa e de distância respeitosa em relação à autoridade, preci- sando circular em diferentes níveis de intimidade com os professores, das conversas descontraídas nos dormitórios e nos encontros casuais nos jardins do colégio às situações mais formalizadas na sala de aula e na capela.

A facilidade com a qual os estudantes transitam entre relações de formalidade e intimidade nega e afirma, simultaneamente, as relações hierárquicas. Essa habilidade relacional, muito mais do que um acúmulo de conhecimento acadêmico (que também existe), é, segundo o autor, um diferencial da escola. Dessa forma, os estudantes aprendem a transitar em uma zona intermediária entre a presunção e o respeito reverencial em relação aos professores, - o que Khan denomina um sentimento de estar à vontade - e em diferentes situações de interação e negociação com a hierarquia. Contudo, nem todos os estudantes apresentam essa desenvoltura. Novamente os bolsistas, sobretudo os estudantes brancos provenientes da classe trabalhadora, apresentam um respeito extremamente reverencial em relação ao colégio e à autoridade, e não são vistos como os mais populares entre os professores, pois eles evidenciam e reforçam a qualidade hierárquica da interação que precisaria ser obnubilada.

Os estudantes não chegaram ao colégio portando esse sentimento de 
estar à vontade em todas as situações de interação. Ao iniciar a etnografia, baseado nas leituras de Bourdieu, o autor imaginava que os estudantes de St. Paul chegariam ao colégio senhores de si, já apresentando uma naturalidade com as mais variadas situações, formais e informais, em função da herança de um capital cultural incorporado pela socialização familiar. Contudo, no trabalho de campo, o autor descobriu que esse pressuposto não se confirmou. Os estudantes chegam ao colégio cabisbaixos, tímidos, parecendo que carregam um peso enorme nos ombros. Somente com o passar do tempo, os rituais da instituição, tais como o jantar semanal com os professores, tornam-se eventos sem segredo para eles.

Os estudantes aprendem aquilo que o autor denominou a "banalidade do excepcional" no colégio por meio de um currículo extremamente diversificado e especializado. Há mais de 100 opções de cursos para os estudantes, oferecendo-lhes oportunidades para se destacar em campos específicos. 0 autor descreve como muitos estudantes eram vistos pelos colegas como um "provável futuro campeão olímpico em squash", ou o "futuro ganhador da medalha Fields" por ser o melhor aluno de matemática da escola, ou ainda um artista que teria seus quadros expostos em grandes museus.
Eles acreditam estar cercados por talentos excepcionais. O cotidiano no colégio, contudo, revelou que os estudantes eram muito mais ordinários. A internet e sites como Wikipedia e resumos no SparkNotes eram utilizados como ataIhos e referências para facilitar a realização dos trabalhos acadêmicos. De toda forma, essa diversidade curricular facilitou a entrada de muitos desses jovens nas universidades da Ivy League, pois cada um deles poderia comprovar que era excelente em determinada área específica. E como as universidades americanas também avaliam a "personalidade" dos estudantes em seus processos de seleção - se eles se destacam nos esportes, nas relações sociais, nas artes etc., e não apenas nos resultados acadêmicos -, essa diversidade de "estudantes excepcionais" em áreas específicas era utilizada pela escola - que possui um grupo de funcionários dedicado somente a essa tarefa - para encaminhá-los às universidades mais prestigiadas dos EUA.

A etnografia de Khan ainda lança luz para as diferenças de gênero e etnia e para a forma como os estudantes negros e as meninas eram vistos como o "outro" exótico ou problemático no colégio. Por exemplo, Khan descreve em detalhes o modo como uma estudante negra, Carla, questiona a meritocracia do colégio. 
Ela faz a questão que não poderia ser enunciada: "se a meritocracia é a base de recrutamento, por que há tão poucos estudantes como eu aqui?” (p. 107). Diferentemente dos colegas que provêm da mesma origem de classe, mas que são brancos, os estudantes bolsistas negros são vistos como "especialistas" na cultura popular, sobretudo nos assuntos mais admirados pelos estudantes: o hip-hop e a dança. Há uma essencialização da "autenticidade" dessa cultura popular associada aos estudantes negros, que os caracteriza como um "outro" no colégio, confinando-os a essa seara e não permitindo que eles naveguem com a mesma naturalidade e facilidade nas searas vistas como mais eruditas da cultura. Dessa forma, o autor demonstra que a experiência do privilégio não é uniforme para os estudantes da elite. 0 gênero e a etnia, assim como a classe, modulam as percepções e as atitudes dos estudantes em relação à escola.

Nesta resenha, enfatizei muito mais como o autor descreveu o aprendizado corporal da hierarquia. Talvez essa forma de ler o trabalho de Khan, muito diferente das resenhas nas revistas estadunidenses, deva-se à minha própria posição de leitor brasileiro. No Brasil, os dilemas retratados por Tocqueville sobre o valor da igualdade na democracia americana devem ser analisados a partir de nossa ênfase nas hierarquias, aqui muito mais toleradas do que alhures (DaMatta, 1979). Se a ideia de uma "sociedade mais aberta" e de uma elite que não quer se apresentar a partir da exclusividade e do monopólio de conhecimentos eruditos pode fazer sentido para os Estados Unidos contemporâneo, no Brasil a situação parece ser diferente, como tem demonstrado a literatura sociológica mais recente sobre os colégios de elite (Almeida, 2009). De toda forma, o trabalho de Khan traz novos ares para a sociologia da educação e pode ser o ponto de partida para certos deslocamentos nas pesquisas sobre os processos de socialização na elite. Talvez o principal deles seja um deslocamento metodológico: ao realizar uma etnografia de um colégio de elite, o autor não se limitou ao que os jovens e a instituição dizem sobre si mesmos, tal como tende a ocorrer em pesquisas baseadas em entrevistas (Jerolmack \& Khan, 2014). Ao observar as interações e os rituais da instituição, o autor demonstrou como certas disposições corporais, como a facilidade em transitar entre diferentes searas culturais, são produzidas no cotidiano. Não se trata aqui tão somente de analisar o antes e o depois da cultura a partir das explicações dos sujeitos, mas seus momentos performáticos nas interações práticas entre os agentes. 


\section{Referências bibliográficas}

Almeida, A. M. F. de. (2009). As escolas dos dirigentes paulistas. Ensino médio, vestibular, desigualdade social. Belo Horizonte: Argvmentvm.

Canêdo, L. B., Almeida, A. M. F., Garcia, A., \& Bittencourt, A. B. (Orgs.). (2004). Circulação internacional $e$ formação intelectual das elites brasileiras. Campinas: Unicamp.

Damatta, R. (1979). Carnavais, malandros e heróis: para uma sociologia do dilema brasileiro. Rio de Janeiro: Zahar.

Jerolmack, C., \& Khan, S. (2014). Talk is cheap: Ethnography and the attitudinal fallacy. Sociological Methods \& Research, 43(2), 178-209.

Nogueira, M. A. (2004, agosto). Favorecimento econômico e excelência escolar: um mito em questão. Revista Brasileira de Educação, 26, 133-184.

Submetido à avaliação em 28 de dezembro de 2014; aceito para publicação em 12 de fevereiro de 2015. 